ConNotas. Revista de crítica y teoría literarias / Vol. V, Núm. 9 / 2007

\title{
Las entrelíneas de la modernidad en El joven de Salvador Novo
}

\author{
RAFAel Yaxal SÁNChez VegA*
}

Resumen:

El joven (1925), de Salvador Novo (1904-1974), es -junto con La Señorita Etcétera de Arqueles Vela- una novela que puede ser considerada fiel testigo de las primeras incursiones de la narrativa hispanoamericana de vanguardia. Se trata, ni más ni menos, de una cápsula de los años veinte en el que se perciben los inicios del ritmo de pensamiento moderno que combina información, erudición, inteligencia, experimentación prosística, cultura clásica, vida cotidiana, actualidad tecnológica, Siglo de Oro, entre otras cosas. La ciudad, como continente de esta selvática diversidad, propia de un paradigma en construcción, deviene elemento fundamental en la composición narrativa de Eljoven. Así, el protagonista de la novela, un auténtico flâneur, atraviesa el espacio citadino y lo desmiembra trozo por trozo para recomponerlo después y hacer de la ciudad una pintura cubista. De esta manera, se puede decir que los rasgos de la modernidad de Eljoven se van deshilvanando mediante la figura del paseante y la ciudad.

Palabras clave:

Flâneur, vanguardias, ciudad, modernidad, novela mexicana.

* El Colegio de México. 


\section{Historia de un joven}

En septiembre de 1923, un año después de la publicación de La Señorita Etcétera, aparecía en La Falange -revista dirigida por Bernardo Ortiz de Montellano y Jaime Torres Bodet- un breve texto titulado ¿Qué México! Novela en la que no pasa nada, firmado por el joven Salvador Novo (1904-1974). En las cuatro páginas que contienen el relato -sin considerar el dibujo de Roberto Montenegro que está intercalado-, Novo describe el paseo de un joven por la Ciudad de México a lo largo de todo un día. Durante la caminata, la ciudad se le presenta a ese joven flâneur en su caótica cotidianeidad. Anuncios, lugares, grupos sociales y personajes de la época son vistos a través de los ojos de un adolescente y de un narrador que no vacilan en hacer juicios sobre la época. Este singular ejercicio de escritura de Novo se incluyó en una sección titulada "Kodak", nombre que alude a la cámara fotográfica que comenzaba a estar de moda en los círculos de la clase media y alta del país. Otras colaboraciones en la misma sección -principalmente las que están firmadas por Porfirio Hernández, "Don Porfirio", y que tienen como título "Instantáneas"- dan cuenta de algunas novedades que la vida moderna desplegaba en la ciudad, ya fueran los escaparates, el cinematógrafo o el klaxon.

Aquella primera “instantánea” que Novo plasmó en iQué México! no sería definitiva. Dos años después, en 1925, aparecía retocada, ampliada, y con otro título, El joven. Novela bistórica. Novela en que no pasa nada. ${ }^{1}$ La nueva versión se distribuyó en tres entregas -de febrero a marzo- en La Antorcha, publicación dirigida por José

\footnotetext{
${ }^{1}$ En esta nueva versión destaca, además del título El joven, el añadido que indica que es una novela histórica. De acuerdo con Saúl Yurkievich, las vanguardias tuvieron tres directrices para una "distribución ordenadora de las manifestaciones de la modernidad": una formalista, otra subjetivista y una realista-historicista. Sobre la última apunta: "La vanguardia concibe la modernidad como culto a la novedad, como afán de participar en el progreso y la expansión provocados por la revolución industrial, como empeño en manifestar el contacto con la historia inmediata, con la microhistoria personal y la macrohistoria colectiva, unánime, como voluntad de gestar una literatu-
} 
Vasconcelos. Los cambios fueron notorios. Novo incorporó párrafos enteros donde las impresiones que el joven protagonista tiene de la ciudad se detallan al igual que el discurso con el que interviene el narrador e incluye tres notas aclaratorias al final. Esta segunda aparición de El joven no sería la última. En agosto de 1928 es publicado nuevamente en un folleto de la serie llamada "La Novela Mexicana", realizada y distribuida por Editorial Popular Mexicana. Los añadidos que Novo había hecho en El joven de 1925 se conservan en su totalidad. Hay pocos cambios, principalmente en algunas alusiones a personajes de la época y en la omisión de las notas finales. ${ }^{2}$ La modificación más importante es la división del texto en once partes mediante viñetas que por momentos separan las opiniones, aparentemente del narrador, y la descripción del recorrido que realiza el protagonista.

La epopeya editorial de El joven no concluye ese año. En 1933, con un tiraje de cien ejemplares numerados no destinados a la comercialización, la novelita de Novo ve la luz nuevamente. El texto sufre pocas variaciones respecto a la edición de 1928. Las viñetas son sustituidas por capitulares, los fragmentos se reducen a diez y son incorporados un epígrafe de D. H. Lawrence y una breve nota introductoria:

Diez años después de escrito El joven, cuando ya ni él ni yo lo somos del todo, le presto atavío decoroso y lo presento en la

ra abierta al mundo, capaz de registrar la cambiante realidad en toda su extensión y en todos sus niveles, que tenga el temple, el ritmo, el nervio de un presente en rápida transformación" (359-360).

${ }^{2}$ Sobre esta nueva edición de El joven, el autor de Dama de corazones comenta: "Cinco años más tarde [Villaurrutia inicia la cronología del texto a partir de 1923 sin tomar en cuenta la versión de 1925] se le fugó una vez en la mala compañía de muchos anuncios, más erratas y precio vil. Anuncios, erratas y bajo precio impidieron, como los árboles, ver el bosque en que se perdió el joven. Intentó una segunda salida con mejores armas. Todo estaba listo. Agustín Lazo trazó los mejores dibujos que se han hecho para un libro mexicano moderno. Y sucedió que la segunda salida no se llevó a cabo. Los dibujos se extraviaron y el joven cambió su billete de salida por un return tickel' (Villaurrutia 684). 
pequeña sociedad de una edición limitada... Fugóseme una vez en la mala compañía de muchos anuncios, más erratas y precio vil. Otra estuvo a punto de adornarse con hermosos dibujos que el Destino extravió [...] No lo publico sino como un pequeño documento histórico, como me pasearía en un modelo 1923, pero respetuoso de los semáforos automáticos, y por la comodidad egoísta de hojearlo, de vez en cuando, y de verme, padre satisfecho, retratado fielmente en un hijo que nació diez años antes que yo. (9-10) ${ }^{3}$

Finalmente, este joven trotacalles encontró su destino como apéndice en la cuarta edición de Nueva Grandeza Mexicana en 1956. El texto es idéntico a la versión de 1928 e incluso respeta la división con viñetas. El único cambio es el nuevo subtítulo que lo acompaña, "Ensayo previo sobre la ciudad escrito en 1928", el cual pareciera hermanarlo con la Nueva Grandęa, que está subtitulada como "Ensayo sobre la Ciudad de México y sus alrededores en 1946". Desde una "novela en que no pasa nada" a una "novela histórica" y de ahí a un "ensayo sobre la ciudad", el itinerario de El joven se muestra no sólo accidentado sino también versátil. Basta con dar un rápido repaso por algunos textos de Novo para advertir las semillas que un joven itinerante sembró por igual en los terrenos de la crónica que en los del ensayo. ${ }^{4}$ Ejemplo de ello serían "Elogio del automóvil” (1926) y la propia Nueva Grandeza Mexicana (1946),

${ }^{3}$ Todas las citas del texto de Novo provienen de la edición de 1933. En adelante indicaré sólo los números de páginas entre paréntesis. Es evidente que Novo estuvo muy al cuidado de la edición -cosa que puede intuirse en la sustitución de las viñetas por letras capitulares que son un tanto más "elegantes"-, pues el tiraje, al ser reducido, pareciera haber sido planeado para que los ejemplares circularan entre amigos o conocidos. Llaman la atención las fechas anotadas en el colofón que indican que El joven fue escrito en 1923 y publicado por primera vez en 1928, olvidando por completo la versión de 1925. No es de extrañar este "vanidoso olvido", ya que ese hijo incómodo contiene más erratas que su hermano tres años mayor que él.

4 "Tal vez sea un error llamar novela a este pequeño libro [Eljoven]. Sus veinte páginas se asemejan más a lo que mi maestro de inglés solía llamar 'ensayo divagador" " (Brushwood 343). 
donde Novo acude a sus impresiones sobre la revolución social que el automóvil trajo consigo, descritas ya en El joven de 1925.

A pesar de este ajetreo editorial, en el que añadidos y supresiones fueron modificándolo discretamente, El joven se mantiene -junto con La señorita etcétera de Arqueles Vela- como un fiel testigo de las primeras incursiones de nuestra narrativa en la vanguardia. Es una cápsula del tiempo de los locos años veinte donde se perciben los inicios del "ritmo de un pensamiento moderno que combina información, erudición, inteligencia, experimentación prosística, cultura clásica, vida cotidiana, actualidad tecnológica, Siglo de Oro y The New Yorker, Wilde y el gossip de la vida citadina" (Monsiváis 766).

Más allá de su recorrido por las imprentas, El joven tiene un tiempo y un espacio definidos: el periodo posrevolucionario -de entreguerras a nivel mundial- y la Ciudad de México. Atrás habían quedado los años de fin de siècle y la belle époque. La década de 1920 atestiguaba el aceleramiento de la modernización en América Latina -que finalmente no dejaría de ser una modernidad periféricainiciada ya en los últimos decenios del siglo XIX y que seguía a marcha forzada el camino trazado por Europa y Estados Unidos. Es el periodo de la "modernización internacionalista" en el que "se fraguan las bases de la actual América Latina” (Rama 105). De igual forma, es la época de los ismos artísticos, de la llamada Vanguardia artística que

impugna la imagen tradicional del mundo (concepción teo, geo, antropocéntrica) y el mundo de la imagen (visión perspectivista, mimesis realista, estética armónico-extensiva). Nace con el vertiginoso remodelado impuesto por la era industrial, era de las concentraciones multitudinarias en las ciudades fabriles, era de las comunicaciones rápidas, de las circulaciones internacionales, de la incorporación de las regiones más remotas al nuevo orden realmente mundial. (Yurkievich 351)

El joven da sus primeros pasos en medio del barullo moderno siguiendo muy de cerca a una Señorita etcétera que se había adentrado 
en las calles de la urbe moderna un año antes. Ambos serían la vanguardia de nuestro Avant-garde narrativo. ${ }^{5}$ Fue entonces que una nueva brújula artística encauzó la Vanguardia hispanoamericana que encontró su aliento en

la metarreflexión sobre las funciones y posibilidades de la literatura en la modernidad (hispanoamericana) y la consiguiente insatisfacción con la práctica literaria establecida de la época, incapaz de respuestas/propuestas válidas frente a la experiencia histórica. (Niemeyer 38)

\section{La Modernidad en entrelíneas}

En el breve ensayo-reseña que Villaurrutia hace de El joven, el autor de Nostalgia de la Muerte comenta: "El joven ha atravesado la ciudad de México, la ha descompuesto trozo por trozo para recomponerla y hacer de ella un todo como un pintor cubista" (686). ${ }^{6} \mathrm{No}$ es aventurado decir que en esas palabras hay ya una lectura en entrelíneas de la novela de Novo que devela tal vez la característica vanguardista más importante del relato, la fragmentación. A partir de ahí, y como una caja china, es posible advertir distintas realizaciones de segmentación que, aunque suene paradójico, dan

${ }^{5}$ Con el Ariel de José Enrique Rodó (1900), la idea de la juventud como una vanguardia intelectual y cultural, promotora de cambio y desarrollo, adquirió un nuevo impulso en Hispanoamérica. Siguiendo esa directriz surgió en México el Ateneo de la Juventud. La novela de Novo está poblada de siluetas juveniles: universitarios, "niños bien", señoritas frívolas y jóvenes que se apropian de diversos espacios como el Sanborn's, las tiendas de discos o alguna fuente de sodas. Los jóvenes son el fermento de la nueva sociedad modernizada; así lo explicita Eljoven: "Deben haber sido los jóvenes, los más perversos del lugar, los que se aventuraran a trepar a una locomotora y aparecieran luego, como el propio enemigo malo, tiznada la cara entre las llamas bramadoras" (20).

${ }^{6} \mathrm{El}$ cubismo fue el arte de "descomponer y recomponer la realidad. Sus principios pudieran sintetizarse así: bidimensionalismo, compenetración de planos, simultaneísmo de visión, color local” (De Torre 235). 
unidad al relato: collages, utilización de recursos cinematográficos como el montaje, rupturas en la línea argumental, yuxtaposición de las experiencias sensoriales, fragmentación de los planos temporales.

Imaginemos, por un momento, que pudiéramos dar a leer Eljoven a un lector del siglo XIX, a una de esas "amigas ideales", por ejemplo, a las que algunos escritores decimonónicos apelaban como remitentes de sus textos. Más allá de los referentes de la época y alguna que otra palabra desconocida, seguramente quedaría desconcertado. ¿Cómo habría de concebir un "gallo higiénico", que los "life-savers tienen el sabor de una extracción de muelas", que la bicicleta es un "ornitorrinco", las boticas son como "haikais" y que los párpados de Emma Padilla están en "tercera velocidad”? Todo ello inmerso en un discurso donde la frontera entre el narrador y el personaje no está claramente definida. La impresión de ruptura con el mundo real le sería inmediata, y es que el "arte de vanguardia ya no intenta "reflejar" la realidad, como lo hacía para avalar su verosimilitud el modelo realista" (Hadatty 33). ${ }^{7}$ Su intención es romper el lazo que une la literatura con la naturaleza, dar giros violentos a la referencialidad y pugnar por una nueva relación entre el arte y la realidad. Con todos estos antecedentes, releamos las entrelíneas de El joven.

El argumento es muy sencillo -otra característica vanguardista es la casi eliminación de lo anecdótico-, pues se reduce al paseo que un joven hace en el transcurso de un día por la Ciudad de México. Con esta información podemos ir deshilvanando ya los rasgos de modernidad en la novela mediante la figura del paseante y la ciudad. Por inicio de cuentas, no se trata de cualquier paseante; es un flâneur, arquetipo surgido en los albores de la modernidad en el siglo XIX:

7 " $\mathrm{El}$ arte postimpresionista es el primero en renunciar por principio a toda ilusión de realidad y en expresar su visión de la vida mediante la deliberada deformación de los objetos naturales. Cubismo, constructivismo, futurismo, expresionismo, dadaísmo y surrealismo se apartan todos con la misma decisión del impresionismo naturalista y afirmador de la realidad... El arte postimpresionista no puede ser ya 
El bulevar es la vivienda del "flâneur" que está como en su casa entre fachadas, igual que el burgués en sus cuatro paredes. Las placas deslumbrantes y esmaltadas de los comercios son para él un adorno de pared tan bueno y mejor que para el burgués una pintura al óleo en el salón. Los muros son el pupitre en el que apoya su cuadernillo de notas. Sus bibliotecas son los kioscos de periódicos, y las terrazas de los cafés balcones desde los que, hecho su trabajo, contempla su negocio. $(\text { Benjamin } 51)^{8}$

Con lo que respecta a la ciudad, ¿qué tan moderna era la capital de México en la década de 1920? En comparación con otras metrópolis, fuera en Estados Unidos o Europa, nuestra ciudad gozaba de una muy incipiente modernidad iniciada ya en el siglo pasado. A pesar de que los grandes edificios tardarían años en fincarse en el centro del país -cosa que no invalidó el refrán: "Fuera de México, todo es Cuautitlán"-, no por ello la ciudad permanecía ajena a la insistencia de ser moderna, hecho que se traducía en

llamado, en modo alguno, reproducción de la naturaleza; su relación con la naturaleza es la de violarla" (Hauser 277).

${ }^{8}$ Es casi imposible no evocar el Ulises de Joyce (1922) cuando se nos presenta un paseante que en un día realiza todo un itinerario: "El día es el protagonista de la novela. La eliminación del argumento es seguida por la eliminación del héroe. En lugar de una fluencia de acontecimientos, Joyce describe una fluencia de ideas y asociaciones; en lugar de un héroe individual, una corriente de conciencia y un monólogo interior infinito e ininterrumpido. El acento se pone siempre en la falta de interrupción del movimiento, en la 'continuidad heterogénea', en la pintura caleidoscópica de un mundo desintegrado. El concepto bergsoniano del tiempo sufre una nueva interpretación, una intensificación y desviación. El acento se pone ahora sobre la simultaneidad de los contenidos de conciencia, la inmanencia del pasado en el presente, el constante fluir junto los diferentes períodos de tiempo, la fluidez amorfa de la experiencia interna, la infinitud de la corriente temporal en la cual es transportada el alma, la relatividad de espacio y tiempo, es decir, la imposibilidad de diferenciar y definir los medios en que el sujeto se mueve" (Hauser 288). Guardando prudentemente las distancias, hay algunos puntos en la descripción de Hauser que coinciden con lo que ocurre en la narración de Eljoven. 
un medio ambiente novedoso: ferrocarriles, máquinas de vapor, fábricas, telégrafos, periódicos, diarios, teléfonos, descubrimientos científicos, centros urbanos que cambiaban la conformación de la sociedad y la distribución de las tradicionales clases sociales. (Rotker 31)

Como consecuencia de la moderna reconfiguración del espacio citadino, las relaciones entre la literatura y la urbe tendrían necesariamente que modificarse. Ya no interesa la ciudad que se describe, sino la ciudad sensorial (Schneider 19). ${ }^{?}$

Sin embargo, más allá de las bondades civilizatorias y utópicas que las ciudades modernas prometían, éstas traían consigo lo que Julio Ramos ha denominado la catástrofe del significante: "La ciudad, ya en Martí, espacializa la fragmentación, que ella misma acarrea, del orden tradicional del discurso, problematizando la posibilidad misma de la representación" (119). La ciudad moderna supone un reto para los escritores, pues queda impregnada de fugacidad y fragmentarismo. ¿Cómo enfrentar un espacio cuya atmósfera es "de agitación y turbulencia, vértigo y embriaguez psíquicos, extensión de las posibilidades de la experiencia y destrucción de las barreras morales y los vínculos personales, expansión y desarreglo de la personalidad, fantasmas en las calles y en el alma"? (Berman 4).

Las vanguardias no fueron las primeras en encarar el problema de la representación citadina. Como lo señala Ramos, la generación modernista tuvo que dar una primera respuesta a la pregunta de cómo ir a la par de lo fugaz y de la realidad desarticulada. La solución fue vislumbrada entonces en las publicaciones periódicas. Basta con echar una mirada a cualquier periódico para notar que su uni-

${ }^{9}$ La ciudad no se mantiene impávida ante la mirada de los escritores, quienes se vieron forzados a reelaborar una literatura urbana en el siglo Xx cuyas características son: "rupturas temporales, juegos tipográficos, las historias van y vienen con impetuosidad, permiten la intromisión de elementos ajenos al discurso literario, tiene una marcada influencia cinematográfica y por lo tanto dejó de ser lineal para entrar en el mundo de los planos diversos" (Avilés 151). 
dad descansa en lo fragmentario y en una efímera temporalidad. Es un medio que encontró su razón de ser en un simulacro de lo real. Si la caótica atmósfera de la modernidad tuvo que recurrir al periódico, para hacer de sí misma algo un poco más tangible, la prensa recurrió, con una misma intención, a la crónica que "fue más el resultado de las circunstancias que de una deliberada preceptiva. $\mathrm{El}$ auge del periodismo de finales de siglo crea una nueva necesidad y esa nueva necesidad un nuevo género" (Yahni 12). La crónica no requería las complejidades técnicas que demanda la novela; reconcilió la voluntad lírica del autor con un nuevo ejercicio de escritura, se adaptó a los espacios de la prensa junto a los tiempos requeridos para su elaboración y enfrentó con éxito el nivel cultural de los lectores. Este género, revitalizado con el trajín moderno de los diarios, "fue el lugar ideal, un lugar sin rígidas fronteras que, como otrora en el púlpito, le permitía [al escritor] hablar en parábolas, contar ejemplos, divagar, soñar, criticar, conversar" (Clark de Lara 72). ${ }^{10}$

El joven tiene ese trasfondo cronístico abierto a la posibilidad de generar un texto híbrido a partir de varias realizaciones prosísticas: narración, descripción, crítica, diálogo. ${ }^{11}$ Sin embargo, a diferencia de los modernistas, Novo no concilia u homogeniza estos diversos "fragmentos" escriturales al mantener su división. José Martí, Manuel Gutiérrez Nájera, Rubén Darío, Amado Nervo, Luis G. Urbina, Enrique Gómez Carrillo, por mencionar tal vez a los más destaca-

${ }^{10}$ La crónica siempre mantuvo fronteras movedizas con otras manifestaciones en prosa como el ensayo, la crítica, el relato, el apunte descriptivo y el poema en prosa de las que "se aprovecha ocasionalmente..., o deriva sin acaso pretenderlo el autor hacia cualquiera de esas modalidades" (Jiménez 546).

${ }^{11}$ A pesar de que nuestra historia literaria haga constantemente un corte entre modernistas y vanguardistas, muchos de los "rechazos y condenaciones vanguardistas forman parte de la génesis del mundo moderno en la sociedad y cultura de América Latina; ellos forman la sustancia de esos lazos secretos y escondidas genealogía de un esquema de desarrollo que puede trazarse desde la crisis del modernismo a las vanguardias, de 1875 al siglo XX” (Schulman 34-35). A mi parecer, Novo estaría en alguna rama del árbol genealógico de la crónica modernista, cuya raíz más profunda en México es Manuel Gutiérrez Nájera. 
dos, tratan de reestablecer la organicidad de un todo tendiendo puentes mediante la subjetividad o la imaginación. De esa forma, Martí, por ejemplo, puede recrear el terremoto de Charleston sin ni siquiera haber estado ahí o Gutiérrez Nájera puede llevar lo que comienza como una crónica local a un relato novelesco en la Novela del tranvía. Fue una generación de escritores que dio a la imaginación el papel que a su juicio debía tener, "no el de inventar sino el de componer los datos de lo real" (García Marruz 221). Novo, por su parte, da un golpe en la quijada a la realidad alterando su representación por medio de lo fragmentario:

Los escritores pueden inclinarse a la antirreferencialidad o bien decidirse por una suprarreferencialidad que, cuestionando la mimesis novecentista y la confianza que su realismo tenía en las relaciones lenguaje-literatura-mundo, no abandona el diálogo con el referente, sino que lo realza hasta exasperarlo. (Barrenechea 381) ${ }^{12}$

En las primeras páginas de El joven, el narrador puntualiza la experiencia del anónimo personaje en las calles de la capital de la siguiente manera: "Todo lo conocía. Solo que su ciudad le era un libro abierto por segunda vez, en el que reparaba hoy más, en el que no se había fijado mucho antes. Leía con avidez cuanto encontraba. ¡Su ciudad! ¡Su ciudad! Estrechábala contra su corazón” (14). ${ }^{13}$ La ciudad es finalmente una lectura fragmentada que se presenta a

${ }^{12}$ En este sentido, Novo iría en dirección opuesta a los cronistas del modernismo que buscaban "rearticular los fragmentos, narrativizando los acontecimientos, buscando reconstruir la organicidad que la ciudad destruía” (Ramos 126). Peter Bürger señala claramente esta diferencia: "El clasicista quiere dar con su obra un retrato vivo de la totalidad; tal es su intención, incluso cuando la parte de la realidad presentada se limita a ser la restitución de una atmósfera fugaz. El vanguardista, por su parte, reúne fragmentos con la intención de fijar un sentido (con lo cual el sentido podría ser muy bien la advertencia de que ya no hay ningún sentido). La obra ya no es producto como un todo orgánico, sino montada sobre fragmentos" (133, las cursivas son mías).

${ }^{13}$ No se menciona en el texto por qué la ciudad es un libro abierto por segunda vez. Probablemente haga alusión al período de enfermedad que el joven ha sufrido 
un joven flâneur que ha decidido tomar un "baño de multitud". ${ }^{14}$ Es un flâneur cronista que "no parte en un rumbo fortuito (aunque así lo haga creer a veces el propio cronista), sino en búsqueda de un itinerario que ilumine la experiencia urbana de su tiempo" (Bencomo 149).

La moderna experiencia citadina del joven incluye el periódico -"Hoy los diarios dan demasiado papel y los hijos de Ford existen demasiado. Hay solicitudes, ofertas, enseñanzas, y aquella fecunda sección de 'Diversos' en 'El País' se ha ramificado clasificando sus cien pies" (18-19)-, los nuevos espacios de reunión -Sanborn's, Lady Baltimore (una fuente de sodas) y Discos Víctor-, las recientes manías - "La soltería, el cinematógrafo, el vegetarianismo, el teléfono y las novelas francesas tienen grande culpa del grupo de las enfermedades mentales" (16)-, ciertos personajes urbanos -choferes, ferrocarrileros, conductores de tranvías, policías- y la creciente influencia norteamericana - ¿Quién que no sepa pronunciar osará comerse un Marshmallow puff?” (15). Finalmente, todo es yuxtapuesto en lo que Ramos llama "la retórica del paseo", en la que

la narrativización de los segmentos aislados del periódico y de la ciudad a menudo se presentan en función de un sujeto que al caminar la ciudad traza el itinerario un discurso- en el discurrir del paseo. El paseo ordena, para el sujeto, el caos de la ciudad, estableciendo articulaciones, junturas, puentes entre espacios (y acontecimientos) desarticulados. De ahí que podamos leer la retórica del paseo como una puesta en escena del principio de la crónica. (Ramos 126)

y de ahí que haya habido una lectura antes y otra después de la convalecencia. El tópico de la enfermedad como antesala de la hipersensibilidad tiene ya sus antecedentes en el simbolismo y la "relectura [acción que haría el joven con la ciudad] entraña siempre la novedad, la sorpresa. Se privilegia, pues, la recepción como momento estético evanescente e irrepetible, sin que la sensación de inacabamiento obste para el disfrute del presente" (Hadatty 49).

14 "No les es dado a todos tomar un baño de multitud: gozar de la muchedumbre es un arte; y ello sólo puede hacerlo, a expensas del género humano, en una francachela de vitalidad, aquel a quien el hada ha insuflado en su cuna el gusto del disfraz y de la máscara, el odio al domicilio y la pasión del viaje" (Baudelaire 47). 
El protagonista de El joven participa en una retórica itinerante con la salvedad de que no traza puentes. Novo ha preferido dejar abiertos los espacios, no hacer uso de costuras y romper con la linealidad articulada del relato convencional.

Una de las partes más "hiperbólicas" de fragmentación y superposición se produce casi al inicio del relato. El joven ya ha salido a recorrer las calles. Lo saludan "avalanchas de zapatos", el "santo olor" del pan, sigue la "pauta de acero de los rieles" de los tranvías y comienza a traducir el ajetreo diario de la urbe con algunos símiles -el sol brillaba "como un reflector", los trenes urbanos eran "como personas decentes", los automóviles "atropellaban los minutos como nuevos ricos" y "los claxons se contestan como gallos". ${ }^{15}$ La narración mantiene su linealidad discursiva en tercera persona hasta que aparece la siguiente enumeración caótica:

Man Spricht Deutsch, Florsheim, Empuje usted, Menú: sopa moscovita. Shampoo, "ya llegó el Taíta del Arrabal”, ejecute con los pies a los maestros, Au Bon Marché, Facultad de México, vías urinarias, extracciones sin dolor, se hace troutrou, examine su vista gratis, diga son-med, Mme. acaba de llegar, estamos tirando todo, hoy, la Reina de los Caribes, The leading Hatters, quien los prueba los recomienda, pronto aparecerá, ambos teléfonos, consígase la novia. Agencia de inhumaciones ever-ready. ¿'Tiene usted callos? Tome Tanlac. Sin duda, a pasos lentos, pero su ciudad se clasificaba. Para cada actividad señalada, remedios o gentes especiales. (14-15)

15 "En la vanguardia iberoamericana no existe un sentido único en que se utilice el símil. Se trata de un manejo extremo, bien distante de la mecánica explicación de un manual de estilística. A grandes rasgos podemos comprender su uso mayoritario, vanguardista o no, como una ruptura dentro del código: la comparación sigue estando, pero ahora es ilógica, sorprendente: se asienta en ocasiones en la cosificación de lo animado, o en la animación de lo yerto (palabras, cosas). Corresponde a una visión del mundo personal, renovadora, distinta. Da una nueva formulación al elemento símil. Su uso puede llegar incluso a una ruptura contra el código: la misma razón de ser convencional del recurso retórico se pierde, cuando comparar no esclarece, sino que opaca” (Hadatty 86). 
El discurso es violentado mediante este alud de impresiones que simultáneamente percibe el joven. La ciudad no ofrece una lectura lineal ni ordenada y así lo plasma el narrador, quien hace caso omiso a la lógica de la enunciación realista. Es casi una puesta en escena del punto número VIII de Actual No. 1, el primer manifiesto estridentista, que apunta: "las ideas muchas veces se descarrilan, y nunca son continuas y sucesivas, sino simultáneas e intermitentes... En un mismo lienzo, diorámicamente, se fijan y se superponen coincidiendo rigurosamente en el vértice del instante introspectivo" (Verani 87). ${ }^{16}$

Más allá de ser una simple enumeración caótica, lo que Novo presenta es un recurso que algunos cubistas utilizaron en sus llamados poemas-conversación, "donde, situadas en el mismo plano, se mezclan percepciones directas, jirones del recuerdo, trozos de diálogos oídos en el café o en la calle, titulares de periódicos; estos últimos equivalentes de los "collages" (De Torre 235). Con este collage, Novo impone un nuevo orden a su discurso y transgrede la búsqueda de organicidad de la "retórica del paseo" cuya intención primera, como ya mencioné antes, es vincular lo fragmentado y devolver la unidad mediante la crónica:

El collage pone en funcionamiento una retórica descompuesta, una contrarretórica; abre el texto a la irrupción deses-

${ }^{16}$ Unas líneas antes, el narrador menciona la presencia en la ciudad de "carteles recientes" con la leyenda "Se prohibe fijar anuncios" (13), lo cual es una clara "referencia al primer manifiesto estridentista que apareció fijado en las paredes de la ciudad en diciembre de 1921, una de cuyas divisas más llamativa, en mayúsculas, fue precisamente 'Se prohíbe fijar anuncios" " (García 304-305). Vicente Quirarte observa una correspondencia entre la enumeración caótica presente en la novela de Novo y el punto VI de ActualNo. 1, al que considera "hermano de la ciudad recorrida en Eljoven de Novo, donde imágenes visuales, auditivas y olfativas se yuxtaponen en el retrato múltiple de la ciudad. La diferencia radica en que la ciudad de Novo está más vitalmente relacionada con el individuo que la camina, la contempla, la asimila, y de tal modo consume el intercambio simbiótico entre hombre y espacio urbano... A la larga, Novo será el más estridentista de los Contemporáneos y en su etapa final, Maples Arce será el más Contemporáneo de los estridentistas” (482-483). 
tructurante de los otros discursos, de los antagónicos; suscita una polución de acontecimientos verbales de valor indeciso que desdibuja lo literario, que lo disuelve en otros discursos o que, al generalizarlo, impide su identificación. La lengua ya no lamina, ya no alisa lo real; evidencia su disparidad, su rivalidad, su discontinuidad. (Yurkievich 235)

Otra manera de leer esta parte del texto es mediante los recursos cinematográficos. Ya desde los primeros comentarios a El joven se habían señalado sus filiaciones con el cine: "Más de un estudiante de leyes compartió conmigo el placer de una proyección privada de aquella cinta cinematográfica que podía intitularse Dieciséis horas de la vida de un joven" (Villaurrutia 684). ${ }^{17}$ La novela de Novo tiene algunas partes claramente estructuradas con el lenguaje fílmico, principalmente mediante el montaje y la secuencia. ${ }^{18}$ En el caso del collage publicitario que nos presenta el autor de Nueva grandeza mexicana, lo que predomina es el montaje, término que se define como

La representación A y la representación B deben ser escogidas entre todos los aspectos del tema que se desarrolla y consideradas de tal manera que su yuxtaposición -la yuxtaposición de esos precisos elementos y no de otros posibles- evoque en la percepción y sentimientos del espectador la más completa imagen del tema. (Eisenstein 53)

${ }^{17} \mathrm{La}$ “"aproximación de los Contemporáneos al cine obedeció, sin duda, al impacto de las vanguardias europeas, sobre todo de los dadaístas y surrealistas, y de autores europeos, Jean Giraudoux y Pierre Girard, y de escritores españoles, Jarnés y el Azorín de Old Spain” (Reyes 151).

18 "Precisamente por desestimar una tradición novelística de pretensiones totalizadoras, el principio fragmentador/analítico del montaje cinematográfico - unido a las novedades en la perspectiva de visión que la cámara de cine aporta- ofrece una herramienta utilísima para la teoría y práctica de la narrativa vanguardista. La lección aprendida por esa prosa está basada en el doble proceso de captar primero la realidad bajo puntos de vista inéditos y, segundo, en la posterior tarea de dotar ese material de un significado que el creador controla mediante el montaje" (Pino 131). 
Novo emplea más de un elemento, pero todos están dentro de un mismo campo de representación, el publicitario. Al yuxtaponerlos, reproduce el frenesí propagandístico en el que está inmersa la ciudad.

Otra parte del texto que ha sido señalada como de clara procedencia fílmica es la siguiente:

(Estos automóviles -iba a escribir con b- se conocieron mucho en el cine; en vistas panorámicas iluminadas, marca Pathé, de pronto daba vuelta un Renault. También en las vistas italianas. A la Hesperia -decana de los argumentos- "pannes" frecuentes le daban ocasión de desesperar desde la portezuela que no podía abrir). (23)

Los paréntesis vuelven a romper la linealidad del discurso para introducir este comentario donde

Novo subraya la naturaleza cinematográfica de las imágenes que el joven va observando al describir la vista panorámica de que pueden disfrutar los conductores de convertibles extranjeros, o sea, mediante la creación de un montaje de proyección de fondo...Colocada en tales automóviles, la cámara de cine pathé proporciona tomas panorámicas a tal grado fascinantes que quien va a bordo del vehículo se ve tentado a abrir la portezuela a fin de lograr una mirada más minuciosa. (Duffey 33)

El relato termina con una secuencia formada con distintos lugares y dividida en cinco párrafos cuyas primeras líneas son: 1) "Sanborn's, "the house of Tiles", se atesta de la misma gente. Hay displicencia en los pedidos y en las actitudes"; 2) "Discos Víctor. Ese joven amable, es, realmente, un tipo de cine"; 3) "Lady Baltimore. El joven de la fuente antes se llamaba precisamente Narciso. Ahora dos niños toman sundaes de cereza, en sillas de juzgado"; 4) "Crisis del paseo en automóviles. Los claxons se contestan como gallos"; y 5) "Las 10. Los teatros se abrían. Los cines supuraban familias. Un tren lo encaminó a su casa. El gendarme 
roncaba. Los chicos incunables se arropan en carteles que ya no sirven". La sucesión de distintos espacios pareciera haber sido producto de un encuadre fílmico. De un lugar pasamos a otro en rápidos saltos que prescinden de algún nexo. ${ }^{19} \mathrm{El} \mathrm{último} \mathrm{de} \mathrm{los} \mathrm{párrafos}$ remata con un montaje en el que las distintas imágenes denotan el final de la jornada.

Una de los rasgos que más ha llamado la atención de El joven es el vaivén narrativo que se produce entre la primera y tercera persona que, a mi parecer, es una forma más de mantener lo fragmentario en el discurso. La confusión que produce esta zigzagueante voz narrativa está en la dilución intra y extradiegética del relato:

Los comentarios del narrador se refieren a su propio yo-aquíahora y se parecen, también por sus repetidas apelaciones a distintos narratarios... a las digresiones extradiegéticas convencionales de un narrador heterodiegético-autorial típico. No obstante, en atención a los contenidos resulta que estos comentarios y observaciones se refieren justamente a los mismos fenómenos que se acaban de presentar en el plano intradiegético, de modo que el aquí y ahora del narrador aparece como idéntico al cronotopos de la diégesis: la Ciudad de México a finales de los años 20. [Por] lo que así se borra otra vez no sólo la diferencia entre extra e intradiegético, sino además entre extra e intraficcional. (Niemeyer 191-192) ${ }^{20}$

19 “'La secuencia constituye una unidad más inédita, más específicamente fílmica aun, la de una acción compleja (aunque única) que se desarrolla en varios lugares y 'salta' los momentos inútiles” (Metz 148).

20 "The most obvious and important experimentation concerns the role of the narrator. As in other works of this period, the experimentation deals with the blurring of the distinction between the narrator, the main character, and the author himself. The narrative is confusing because it is difficult to know definitely whose opinion is expressed. The implied author and the narrator interject their own opinions and/or question the validity of their perceptions, all under the guise of narrating what the young man thinks and sees. More importantly, the narrator and the implied author are allowed self-reflexivity and therefore interject personal comments and reactions in first person" (Aguirre 165-166). 
La confusión entre los planos interiores y exteriores de la obra ha llegado incluso a ser motivo para calificarla como novela autobiográfica (Quirarte 450). ${ }^{21}$

Mediante la intromisión del discurso libre indirecto -aunque no habría mucho problema si lo consideráramos como monólogo interior, discurso doxal o voz en off, para seguir con el influjo cinematográfico- se introducen los comentarios irónicos y las críticas a la época. Es también la voz que pondera el pasado y el presente: "Anteriormente a la revolución, podía leerse entero el periódico, y se podían atravesar las calles. Hoy los diarios dan demasiado papel y los hijos de Ford existen demasiado" (18). Otra forma que el narrador emplea para emitir sus juicios entre el antes y el ahora es la marca adverbial 'ya': "Ya los helados no son solamente de limón, de chocolate, de fresa o de 'amantecado' como solían" (15); "Ya los ungüentos no gozan del prestigio que hurtaban a los cirujanos”(16); “Esto ya no lo pueden leer las familias” (19); "Ya no quieren que los apoden 'el elefante', el 'filder' ni el 'cachafas'. Me llamo Manuel, dicen” (28); "Ya nada les inmuta” (28). La misma forma adverbial también sirve para dar los saltos en el discurso narrativo en tercera persona: "En fin, estaba ya en la calle" (12), "Ya estaba en la escuela" (32), "Ya obscurecía sobre la ciudad" (52).

El joven ha recorrido la ciudad, ha regresado al pasado mediante sus recuerdos y ha servido de vehículo expresivo a un narrador que lúdicamente se confunde con su personaje. La experiencia urbana del cronista termina en la propia voz del protagonista: "-Lo que hice hoy -dijo el joven soltando sus zapatos- no tendrá ya

${ }^{21}$ Este señalamiento no sería aventurado si recordamos la definición de novela autobiográfica: "llamaré así [novela autobiográfica] a todos los textos de ficción en los cuales el lector puede tener razones para sospechar, a partir de parecidos que cree percibir, que se da una identidad entre el autor y el personaje, mientras que el autor ha preferido negar esa identidad o, al menos, no afirmarla" (Lejeune 63). Al respecto, Rosa García señala: “en Eljoven de 1923 narrador y personaje parecían ser uno solo y autobiográfico, en el de 1928 son dos: el protagonista es el Novo de 1923, mientras que el narrador es un Novo distinto, cinco años mayor, que mira con distancia y cariño, también con ironía y escepticismo, al primero" (García Gutiérrez 304). 
objeto mañana. Hay cosas invariables, que gustan siempre. Tengo sueño. Siempre me gustará dormir, pero mañana se habrá muerto alguien" (56). ¿No es esto el dejo de la modernidad, siempre fugaz e intangible, al desvanecerse en el aire?

Para finalizar, quiero señalar la necesidad de una edición confiable, crítica y que dé cuenta de la historia textual de este peculiar relato de Novo. Ante la falta de un manuscrito, por ahora sólo nos queda acudir a sus distintas ediciones de las cuales ninguna se salva de las erratas que pueden adjudicarse más a los editores que al propio Novo. De igual forma, en todas ellas la puntuación varía al igual que el uso de cursivas, negritas o comillas para destacar, generalmente, anglicismos o galicismos. A lo anterior habría que sumar que la edición de 1933 tiene un epígrafe de D. H. Lawrence y una pequeña nota introductoria de Novo y que la de 1925 tiene tres notas aclaratorias también de la pluma de Novo. El problema no deja de ser menor con las antologías que recuperan El joven, pues también ellas dan diferentes versiones. Hugo Verani, en su Narrativa vanguardista hispanoamericana (1996), se basa en la edición de 1928. Cristopher Domínguez Michael, en la Antología de la narrativa mexicana del siglo XX (1996), rescata una versión perteneciente a una edición de 1986 de la Nueva grandeza mexicana. Guillermo Sheridan -Homenaje a los Contemporáneos: monólogos en espiral, antología de narrativa (1982) - recupera la que apareció en Toda la prosa (1967) de Salvador Novo al igual que el Fondo de Cultura Económica, que la incluye en el primer tomo de la obra ensayística de Novo titulada Viajes y ensayos (1996). Si cotejamos estas versiones antologadas con las supuestas fuentes también es posible advertir cambios, ya sea que se hayan hecho para enmendar erratas o para clarificar un poco la puntuación.

Una característica del texto de Novo que ha pasado desapercibida completamente es que tipográficamente está seccionado. Las versiones de 1928 y 1933 están divididas en once partes mientras que la de 1956 tiene sólo ocho. Las divisiones están marcadas con viñetas en las ediciones del 28 y del 56 y con capitulares al inicio de cada fragmento en la versión del 33. Este detalle es de importancia, pues las divisiones sirven para deslindar las opiniones del narrador 
de la descripción del recorrido que realiza el anónimo protagonista. Sólo Domínguez Michael rescata esta particularidad del texto marcando unos blancos entre cada fragmento.

Novo siempre consideró la versión del 28 como la primera publicación de El joven. En el colofón de la edición del 33 se advierte: "El joven fue escrito en MCMXXIII y publicado por primera vez en MCMXXVIII”. ¿Qué ocurre con la versión de 1925? No es de extrañar que Novo renegara de ese hijo incómodo, pues es el que más erratas tiene. No obstante, si lo comparamos con las ediciones que le siguieron, esta versión fue la que sufrió más cambios, pues Novo suprimió líneas enteras, quitó algunos nombres de personajes de la época y también se deshizo de las tres notas que acompañaban el texto. Una moderna edición de El joven debe dar cuenta de todos estos cambios. Debe ingeniárselas también para señalar las distintas divisiones del texto, fijar una puntuación y establecer un aparato de notas aclaratorias que ayude a la comprensión del texto. Curiosamente, en la nota final de la versión del 25, Novo confiesa: "Al proponerme añadir, para actualizarlo, notas de este viejo relato de dos años, imaginé que tendría que escribirle muchas. No han sido sino, en realidad, estas tres las indispensables". Un lector de este nuevo siglo indudablemente requiere más de tres notas que le ayuden a ubicar lugares, identificar personalidades y entender las costumbres y modas de la sociedad de aquellos años. En ese sentido, El joven ya no lo es del todo. No obstante, valdría la pena intentar darle a ese joven un "atavío decoroso" - como Novo lo intentó con su edición de 1933- para presentarlo nuevamente en sociedad.

\section{Bibliografía}

Aguirre Rehbein, Edna. "Vanguardist Techniques in Mexican Prose Fiction: 1923-1962." Tesis doctoral. University of Texas, 1988. Avilés Fabila, René. "Literatura y ciudad." Revista Mexicana de Ciencias Politicas y Sociales 111-112 (1983): 151-155.

Barrenechea, Ana María. "La crisis del contrato mimético en los textos contemporáneos.” Revista Iberoamericana 118-119 (1982): 377-381. 
Baudelaire, Charles. "Las multitudes." El spleen de Paris. Tr. Margarita Michelena. México: FCE, 2000. 47-48.

Bencomo, Anadeli. "Subjetividades urbanas: mirar/contar la urbe desde la crónica." Iberoamericana 11 (2003): 145-159.

Benjamin, Walter. Iluminaciones II: Baudelaire, un poeta en el esplendor del capitalismo. Tr. Jesús Aguirre. Madrid: Taurus, 1972.

Berman, Marshall. Todo lo sólido se desvanece en el aire. La experiencia de la modernidad. México: Siglo XXI, 2004.

Brushwood, John, S. México en su novela. Una nación en busca de su identidad. Tr. Fernando González Aramburo. México: FCE, 1998.

Bürger, Peter. Teoría de la vanguardia. Tr. Jorge García. Barcelona: Península, 1987.

Clark de Lara, Belem. Tradición y modernidad en Manuel Gutiérrez. Nájera. México: UNAM, 1998.

Duffey, Patrick. De la pantalla al texto. La influencia del cine en la narrativa mexicana del siglo veinte. Tr. Ignacio Quirarte. México: UNAM, 1996.

Eisenstein, Sergei. El sentido del cine. México: Siglo XXI, 1986.

García Gutiérrez, Rosa. Contemporáneos: la otra novela de la revolución mexicana. Huelva: Universidad de Huelva, 1999.

García Marruz, Fina. "La prosa poemática en Martí.” Temas martianos. La Habana: Biblioteca Nacional José Martí. Departamento Colección Cubana, 1961: 215-239.

Hadatty Mora, Yanna. Autofagia y narración. Estrategias de representación en la narrativa iberoamericana de vanguardia, 1922-1935. Madrid: Vervuert/Iberoamericana, 2003.

Hauser, Arnold. Historia social de la literatura y el arte. Vol. 3. Madrid: Guadarrama, 1969.

Jiménez, José Olivio. "El ensayo y la crónica del modernismo." Historia de la literatura hispanoamericana II: Del neoclasicismo al modernismo. Coord. Luis Íñigo Madrigal. Madrid: Cátedra, 1987. 537548.

Lejeune, Philippe. Elpacto autobiográfico y otros estudios. Tr. Ana Torrent. Madrid: Megazul-Endymion, 1994. 
Metz, Christian. "La gran sintagmática del film narrativo." Análisis estructural del relato. Buenos Aires: Tiempo Contemporáneo, 1970. 147-153.

Monsiváis, Carlos. "De la santa doctrina al espíritu público (sobre las funciones de la crónica en México)." Nueva Revista de Filología Hispánica 35 (1987): 753-771.

Niemeyer, Katharina. Subway de los sueños, alucinamiento, libro abierto. La novela vanguardista hispanoamericana. Madrid: Vervuert/Iberoamericana, 2004.

Novo, Salvador. El joven. México: Imprenta Mundial, 1933.

Pino, José M. del. Montajes y fragmentos: una aproximación a la narrativa española de vanguardia. Amsterdam: Rodolpi, 1995.

Quirarte, Vicente. Elogio de la calle. Biografía literaria de la Ciudad de México, 1850-1992. México: Cal y Arena, 2004.

Rama, Ángel. La ciudad letrada. Hanover: Ediciones del Norte, 1984. Ramos, Julio. Desencuentros de la modernidad en América Latina. Literatura y politica en el siglo XIX. México: FCE, 1989.

Reyes, Aurelio de los. "Aproximación de los Contemporáneos al cine." Los Contemporáneos en el laberinto de la crítica. Eds. Rafael Olea Franco y Anthony Stanton. México: COLMEX, 1994. 149-171.

Rotker, Susana. La invención de la crónica. México: FCE, 2005.

Schneider, Luis Mario. El estridentismo, 1921-1927. México: UNAM, 1985.

Schulman, Iván A. "Las genealogías secretas de la narrativa: del modernismo a la vanguardia." Prosa bispánica de vanguardia. Ed. Fernando Burgos. Madrid: Orígenes, 1986. 29-41.

Torre, Guillermo, de. Historia de las literaturas de Vanguardia. Vol. 1. Madrid: Guadarrama, 1971.

Verani, Hugo J. Las vanguardias literarias en Hispanoamérica. Manifiestos, proclamas y otros escritos. México: FCE, 1995.

Villaurrutia, Xavier. "Seis personajes." Obras. 2a ed. México: FCE, 1966. 667-686.

Yahni, Roberto. Prosa modernista hispanoamericana. Antología. Madrid: Alianza, 1974.

Yurkievich, Saúl. "Los avatares de la vanguardia." Revista Iberoamericana 118-119 (1982): 351-366. 